\title{
Correlation of Water Frost Porosity in Laminar Flow over Flat Surfaces \\ (Running Head: Water Frost Porosity in Laminar Flow)
}

Max Kandula

ASRC Aerospace, John F. Kennedy Space Center, FL 32899, USA

E-mail address: max.kandula-1@nasa.gov

\begin{abstract}
A dimensionless correlation has been proposed for water frost porosity expressing its dependence on frost surface temperature and Reynolds number for laminar forced flow over a flat surface. The correlation is presented in terms of a dimensionless frost surface temperature scaled with the cold plate temperature, and the freezing temperature. The flow Reynolds number is scaled with reference to the critical Reynolds number for laminar-turbulent transition. The proposed correlation agrees satisfactorily with the simultaneous measurements of frost density and frost surface temperature covering a range of plate temperature, ambient air velocity, humidity, and temperature. It is revealed that the frost porosity depends primarily on the frost surface and the plate temperatures and the flow Reynolds number, and is only weakly dependent on the relative humidity. The results also point out the general character of frost porosity displaying a decrease with an increase in flow Reynolds number.
\end{abstract}

Key Words: Water frost, frost density, frost porosity, porous media, temperature and Reynolds number dependence 


\section{Nomenclature}

$c_{p}$ specific heat at constant pressure, $\mathrm{kJ} / \mathrm{kg} . \mathrm{K}$

Fo Fourier number, $\alpha_{\infty} t / L^{2}$

$h_{m}$ average heat transfer coefficient, $\mathrm{W} / \mathrm{m}^{2} . \mathrm{K}$

$k$ thermal conductivity, W/m.K

$L$ plate length, $\mathrm{m}$

$N u_{m}$ average Nusselt number, $h_{m} L / k_{\infty}$

Pr Prandtl number of air, $c_{p} \mu_{\infty} / k_{\infty}$

Re flow Reynolds number, $u_{\infty} L / v_{\infty}$

$t$ time, sec

$T$ temperature, $\mathrm{K}$

$T_{f}$ frost temperature, $\mathrm{K}$

$T_{\infty}$ freestream temperature, $\mathrm{K}$

$u_{\infty}$ freestream velocity, $\mathrm{m} / \mathrm{s}$

$x$ axial distance from the leading edge of the plate, $\mathrm{m}$

\section{Greek Symbols}

$\alpha$ thermal diffusivity, $\mathrm{m}^{2} / \mathrm{s}$

$\phi$ relative humidity

$\theta$ dimensionless frost surface temperature, $\left(T_{f_{s}}-T_{w}\right) /\left(T_{m}-T_{w}\right)$

$\psi$ frost porosity 
$\mu$ dynamic viscosity, $\mathrm{kg} / \mathrm{m} . \mathrm{s}$

$v$ kinematic viscosity, $\mu / \rho\left(\mathrm{m}^{2} / \mathrm{s}\right)$

$\rho_{f}$ average frost density, $\mathrm{kg} / \mathrm{m}^{3}$

$\omega$ humidity ratio (absolute humidity) of moist air, $\mathrm{kg}$ (water vapor)/kg(dry air) $\xi=\mathrm{Re} / \mathrm{Re}_{c}$

\section{Subscripts}

$\infty$ ambient (freestream, moist air)

$c$ critical (laminar-turbulent transition)

$f$ frost

$g$ air-vapor mixture

$m$ freezing

$w$ plate wall

$f s$ frost surface

\section{Introduction}

Frost formation represents an important consideration in cryogenics, refrigeration, aerospace, meteorology and various process industries. Processes involving simultaneous heat transfer and frost formation are occasioned in gas coolers, refrigerators, regenerators, freeze-out purification of gases, cryopumping, and the storage of cryogenic liquids.

Frost forms when moist air comes in contact with a cold surface maintained at a temperature which is below the freezing temperature of water $(273 \mathrm{~K})$ and is less than the dew point temperature, so that water vapor directly passes from a gaseous state to solid state (ice) releasing the latent heat of sublimation. Water frost represents a complex porous 
medium comprised of ice particles randomly distributed in air-water vapor mixture (Fig. 1). The frost growth (characterized by a moving boundary) and the densification are governed by heat and mass diffusion processes within the frost layer and at the frost-air interface.

Frost offers significant thermal resistance to heat transport in heat exchangers, and increases the pressure drop by flow restriction. Frost/icing on aircraft wings causes significant aerodynamic penalties in lift and drag, leading to a decrease in lift and an increase in drag. Frost/ice formation on cold fuel/oxidizer tanks and other components may cause debris concerns when it is shed on critical components of aerospace vehicles. The prediction of frost growth is thus of great practical importance.

The frost porosity $\psi$ is directly related to the frost density $\rho_{f}$ by the relation

$$
\psi=\frac{1-\rho_{f} / \rho_{\text {ice }}}{1-\rho_{g} / \rho_{\text {ice }}}
$$

where $\rho_{\text {ice }}$ is the density of ice, and $\rho_{g}$ the density of air-vapor mixture. Note that $\rho_{\text {ice }}$ is usually taken as $917 \mathrm{~kg} / \mathrm{m}^{3}$. In traditional porous packed beds, the effective thermal conductivity is modeled as a function of porosity $\psi$ (see Cheng and Hsu, 1999).

The calculation of frost growth requires information concerning the average frost density and effective frost thermal conductivity. During frost formation, frost thickness, frost density, frost thermal conductivity, and frost surface temperature increase continuously (Fig. 1). Generally, the frost thermal conductivity is correlated with frost density (Östin and Anderson, 1991), with additional dependence on the frost surface temperature and atmospheric variables including air velocity, air humidity, and air temperature. Whereas several theoretical models have been proposed for the prediction of 
frost thermal conductivity as a function of frost density (or frost porosity) and frost surface temperature (Kandula 2010), published work on the frost density dependence is relatively small. Inaccuracies in the frost porosity could lead to significant errors and uncertainties in the predicted frost thickness and frost surface temperature.

Experimental studies (for example, Sahin 1994) have shown that the frost density depends on frost surface temperature, plate temperature, and additionally on air velocity, air humidity, and air temperature. Theoretical considerations suggest that the frost surface temperature in turn depends on the plate temperature, and the atmospheric variables governing heat and mass transport at the frost surface (Cheng and Cheng, 2001). Generally, frost density is known to increase with an increase in flow Reynolds number (Sahin 1994). Measurements by Östin and Anderson (1991) suggest that the frost thickness depends strongly on the cold plate temperature and the air humidity. Higher plate and air temperatures lead to denser frosts, while higher humidity ratios produce lower frost density (Sahin 1994).

When the frost surface approaches a constant value with time (below the melting temperature), a quasi-steady condition prevails. If the surface temperature approaches the freezing temperature, a cyclic increase (small) in frost thickness is manifested, and is accompanied by a large and abrupt increase in frost density (Östin and Anderson, 1991). A corresponding increase (jump) in the thermal conductivity of frost was also noticed. Melting at the frost surface was also reported by other investigators (Trammel et al., 1967; Aoki, 1983; Cheng and Wu, 2003).

Brian et al. (1969) point out that forced convection frosts formed at relatively high temperatures are endowed with densities ranging from 300 to $500 \mathrm{~kg} / \mathrm{m}^{3}$, while natural 
convection frosts at low temperatures are usually light and fluffy with densities between 10 and $50 \mathrm{~kg} / \mathrm{m}^{3}$. This is to be expected primarily because heat and mass transfer coefficients in forced convection are considerably higher relative to those in natural convection.

In view of the complex processes connected with the heat and mass transfer processes within the frost layer (regarded as a porous medium), most correlations for frost density are essentially empirical. Early correlations proposed for frost density are formulated in dimensional form, restricting their generality. The correlation due to Hosoda and Uzuhashi (1967) expresses the frost density in terms of plate temperature (power-law) and air velocity without regard to the frost surface temperature. A widely considered correlation due to Hayashi et al. (1977) expresses frost density as an exponential function of frost surface temperature alone, with no consideration for the plate temperature. Hermes et al. (2009) present a frost density correlation as an exponential function of both frost surface temperature and plate temperature, but exclude the effect of atmospheric variables.

Among other correlations, Biguria and Wentzel (1970) proposed a frost density correlation in a mixed mode (semi-dimensionless form) in terms of a dimensionless frost surface temperature (scaled with respect to plate temperature and melting temperature), and dimensional parameters, namely, the plate temperature, air velocity, and air humidity. In recent times, increasing emphasis is directed towards the development of frost density correlations in fully dimensionless form. Yang and Lee (2005) proposed a correlation for frost density with dimensionless frost surface temperature (scaled with plate temperature, melting temperature and air temperature), air humidity ratio, Reynolds number, and Fourier number. It is evident that correlations involving Fourier number (dimensionless time) seem to be less general, as they impose a limitation on the range of frosting times encountered in 
actual applications. Also, the use of air temperature in scaling the frost surface temperature does not lend to a general representation of the full range of frost surface temperature (starting from the plate temperature initially to the melting temperature eventually).

It is the purpose of this note to examine the dependence of frost density variation with frost surface temperature, the plate temperature, and the flow Reynolds number in the laminar regime. Existing experimental data on simultaneous measurements of frost density and frost surface temperature is examined, and a new correlation for frost density in forced flow over flat surfaces is proposed that is applicable to a full range of frost surface temperature and flow velocity (within the laminar limit).

\section{Existing Correlations for Frost Density}

An excellent summary of the various correlations for the thermophysical properties of frost (density and thermal conductivity) is presented by Yang and Lee (2004), indicating their range of validity. The geometries considered include flat plate, vertical plate, horizontal parallel plates, and cylindrical tubes. Iragorry et al. (2004) provided a critical review of frost properties (density, thermal conductivity, frost thickness, and convective heat transfer) along with frost growth models. The frost density correlations considered the geometries of flat plates and vertical plates.

Hosoda and Uzuhashi (1967) present a correlation for frost density in terms of plate temperature and flow velocity as:

$$
\rho_{f}=340\left|T_{w}\right|^{-0.445}+85 u_{\infty}
$$

where the frost density $\rho_{f}$ is in $\mathrm{kg} / \mathrm{m}^{3}, T_{w}$ is the plate temperature $\left({ }^{0} \mathrm{C}\right)$, and $u_{\infty}$ is the air velocity in $\mathrm{m} / \mathrm{s}$. This correlation is valid for $-20 \leq T_{w} \leq-5^{0} \mathrm{C}, 0 \leq T_{\infty} \leq 10^{0} \mathrm{C}, 1 \leq u_{\infty} \leq 5$ 
$\mathrm{m} / \mathrm{s}, 0.0188 \leq \omega_{\infty} \leq 0.00604 \mathrm{~kg}$ (vapor) $/ \mathrm{kg}$ (dry air), and $0 \leq t \leq 240 \mathrm{~min}$, where $\omega_{\infty}$ stands

for the air humidity and $t$ for the time.

Biguria and Wentzel (1970) proposed a correlation of the form

$$
\rho_{f}=f\left(\frac{T_{f s}-T_{w}}{T_{m}-T_{w}}, T_{w}, u_{\infty}, \omega_{\infty}, x\right)
$$

where $T_{f s}$ is the frost surface temperature, $T_{m}$ the melting temperature $\left({ }^{\circ} \mathrm{C}\right.$ for water $), x$ is the distance from the leading edge of the flat plate. This correlation is valid for their test conditions: $-96 \leq T_{w} \leq-29{ }^{\circ} \mathrm{C}, 26 \leq T_{\infty} \leq 310^{\circ} \mathrm{C}, 2.7 \leq u_{\infty} \leq 12.5 \mathrm{~m} / \mathrm{s}$, $0.0065 \leq \omega_{\infty} \leq 0.0135 \mathrm{~kg}$ (vapor) $/ \mathrm{kg}$ (dry air), and $0 \leq t \leq 50 \mathrm{~min}$.

Hayashi et al. (1977) proposed the following correlation for the frost density as a function of frost surface temperature only:

$$
\rho_{f}=650 \exp \left[0.227\left(T_{f s}-273.15\right)\right] \quad \text { • }
$$

where $\rho_{f}$ is in $\mathrm{kg} / \mathrm{m}^{3}$, and $T_{f s}$ is in degrees Kelvin. Eq. (4) is widely considered for frost growth modeling (see for example, Cheng and Cheng, 2001; Sherif et al., 1993). It is applicable for $-18.6{ }^{\circ} \mathrm{C}<T_{f s}<-5{ }^{\circ} \mathrm{C}$, air stream velocities $u_{\infty}$ in the range of $2-6 \mathrm{~m} / \mathrm{s}$, an airstream humidity ratio $\omega_{\infty}$ of $0.0075 \mathrm{~kg}$ (vapor) $/ \mathrm{kg}$ (dry air), and $t=0$ to $450 \mathrm{~min}$.

Fig. 2a shows graphically the variation of frost density as a function of frost surface temperature according to Eq. (4). This correlation is known to predict unacceptably higher values of frost density for frost surface temperatures within about $5 \mathrm{~K}$ below the freezing temperature, with increasing error as the frost surface approaches the freezing temperature (Iragorry et al., 2004). Hermes et al. (2009) point out that the correlation of Hayashi et al. (1977) overpredicts the frost density in comparison with the measurements (Fig. 2b). 
Another limitation of Hayashi et al.'s correlation is ascribed to its dependence on surface temperature only without regard to the plate temperature.

Yang and Lee (2005) suggest a correlation for frost density of the form:

$$
\frac{\rho_{f}}{\rho_{\text {ice }}}=f\left(\frac{T_{f s}-T_{m}}{T_{m}-T_{w}}, \operatorname{Re}, \omega_{\infty}\right)
$$

In Eq. (5a), the Reynolds number Re and the Fourier number $F o$ are defined by

$$
\operatorname{Re}=u_{\infty} L / v_{\infty}, \quad F o=\alpha_{\infty} t / L^{2}
$$

Their correlation is limited to $-5 \leq T_{\infty} \leq 15^{\circ} \mathrm{C},-35 \leq T_{w} \geq-15^{\circ} \mathrm{C}, 1.0 \leq u_{\infty} \geq 2.5 \mathrm{~m} / \mathrm{s}$, and $0.00322 \leq \omega_{\infty} \leq 0.00847 \mathrm{~kg}$ (vapor) $/ \mathrm{kg}$ (dry air). The dependence of frost density on the dimensionless frost surface temperature is of the exponential form, indicating a strong dependence of frost density on the frost surface temperature.

Hermes et al. (2009) recently considered a frost density correlation of the form:

$$
\rho_{f}=a \exp \left(b T_{f_{s}}+c T_{w}\right)
$$

where the constants $a, b, c$ are evaluated by comparison with their test data as:

$$
a=207.3, \quad b=0.266, \quad c=0.0615
$$

The range of their measurements is: $-16 \leq T_{w} \geq-4{ }^{\circ} \mathrm{C}, 16 \leq T_{\infty} \leq 22^{\circ} \mathrm{C}, u_{\infty}=0.7 \mathrm{~m} / \mathrm{s}$, and $50 \leq \phi_{\infty} \leq 80 \%$, where $\phi_{\infty}$ is the relative humidity.

\section{Proposed Correlation for Frost Density}

As the frost thickness increases, it becomes imperative that we account for both frost surface temperature and plate temperature in contributing to the variation of frost density. On the basis of their observations concerning frost density measurements, Biguria and Wentzel (1970) originally suggested that the density could be correlated with both plate 
temperature and frost surface temperature (see Eq. 3). Since frost surface temperature depends on the air parameters (air temperature, air humidity and air velocity), it is to be expected that the dependence of frost density on the air temperature and air humidity (thermodynamic state variables) can be indirectly accounted for by the frost surface temperature. Also the effect of time is expected to be absorbed through the frost surface temperature, which is known to increase monotonically with time.

Considering the joint effects of frost surface temperature and air velocity, we proceed with a correlation for frost density in the form

$$
\begin{gathered}
\frac{\rho_{f}}{\rho_{\text {ice }}}=f(\theta, \xi)=c_{1} \theta \exp \left\{-\left[c_{2}+c_{3}(1-\theta)\right]\left(1-\xi^{c_{4}}\right)\right\} \\
\theta=\frac{T_{f s}-T_{w}}{T_{m}-T_{w}}, \quad \xi=\frac{\operatorname{Re}}{\operatorname{Re}_{c}}
\end{gathered}
$$

In the preceding equation, $\theta$ is the dimensionless frost surface temperature, and $\operatorname{Re}_{c}$ is the critical Reynolds number for laminar-turbulent transition. The choice of the dimensionless frost surface temperature, as defined in Eq. ( $7 b)$, is adapted from Biguria and Wentzel (1970). A value of $\operatorname{Re}_{c} \approx 10^{5}$ is considered in the present work, based on available measurements on frost formation (Biguria and Wentzel, 1970; Yang et al., 2006) and considering the roughness of the frost surface. For a detailed account concerning the role of surface roughness in laminar-turbulent transition, Schlichting (1979) and White (1991) may be consulted.

Equation (7a) satisfies the requirement that

$$
\rho_{f} / \rho_{\text {ice }}=0 @ \theta=0
$$


Considering a maximum possible frost density of $500 \mathrm{~kg} / \mathrm{m}^{3}$ for pre-melting frosts in the laminar forced flow (Brian et al., 1970), we may consider that

$$
c_{1}=0.5
$$

so that

$$
\rho_{f} / \rho_{\text {ice }}=0.5, \quad @ \theta=1, \xi=\operatorname{Re} / \operatorname{Re}_{c}=1
$$

Heat transfer in a laminar boundary layer past a flat plate is well-correlated by (Kays and Crawford, 1980)

$$
N u_{m}=0.664 \mathrm{Re}^{0.5} \operatorname{Pr}^{1 / 3}, \quad \operatorname{Pr}>0.6
$$

where the average Nusselt number $N u_{m}$ and the Prandtl number Pr are defined by

$$
N u_{m}=h_{m} L / k_{\infty}, \quad \operatorname{Pr}=c_{p \infty} \mu_{\infty} / k_{\infty}
$$

The quantity $h_{m}$ is the average convective heat transfer coefficient, and $k_{\infty}$ the thermal conductivity of moist air. Eq. (9a) suggests that the constant $c_{4}$ can be reasonably represented by

$$
c_{4}=0.5
$$

The remaining constants $c_{2}, c_{3}$ are to be determined by a comparison of Eq. ( $\left.7 \mathrm{a}\right)$ with the detailed measurements of Hermes et al. (2009).

\section{Results and Discussion}

4.1 Correlation with the Data of Hermes et al. (2009)

Hermes et al. (2009) recently obtained elaborate measurements of frost growth and densification processes. A total of 12 test runs were conducted for frost density measurements for a range of parameters: $T_{w}=-5^{0}, 10^{\circ},-15^{\circ} \mathrm{C}, T_{\infty}=16{ }^{\circ} \mathrm{C}$ and $22{ }^{\circ} \mathrm{C}, \phi_{\infty}=$ $50 \%$ and $80 \%, u_{\infty}=0.7 \mathrm{~m} / \mathrm{s}$, and $t=60 \mathrm{~min}$ and $120 \mathrm{~min}$. The data are obtained on an aluminum plate. An electronic scale was used to measure the mass of frost deposited. T- 
type thermocouples were used to measure temperature. An infrared camera was also used to measure the frost surface temperature $\left( \pm 0.2^{0} \mathrm{C}\right)$. The frost thickness was measured by image processing ( $\pm 5 \mu m$ uncertainty). The overall uncertainties in frost thickness and frost density are $\pm 2 \%$ and $\pm 5 \%$ respectively.

Figure 3 presents a correlation of Eq. (7a) with the measured frost density of Hermes et al. (2009). The frost density data for $t=60 \mathrm{~min}$ and $t=120 \mathrm{~min}$ are presented in a dimensionless form with $\rho_{f} / \rho_{i c e}$ as a function of dimensionless frost surface temperature $\theta$. The correlation constants $c_{2}, c_{3}$ are evaluated as

$$
c_{2}=0.376, c_{3}=1.5
$$

Thus the frost density correlation takes the form

$$
\frac{\rho_{f}}{\rho_{\text {ice }}}=0.5 \theta \exp \left\{-[0.376+1.5(1-\theta)]\left(1-\xi^{0.5}\right)\right\}
$$

Equation (12) is seen to correlate well with the data covering dimensionless temperature $\theta$ from about 0.45 to 1.0 . Note that $\theta \rightarrow 0\left(T_{f s}=T_{w}\right)$ physically corresponds to the condition of very early frost growth, when the frost temperature is very close to the plate temperature. On the other extreme, $\theta \rightarrow 1\left(T_{f s}=T_{m}=0^{\circ} \mathrm{C}\right)$ physically represents the situation when the frost surface attains the melting temperature. It is observed that the data for $t=120 \mathrm{~min}$ generally shift to the right (increasing $\theta$ ) relative to that at $t=60 \mathrm{~min}$. This is to be expected since both the frost surface temperature and frost density increase with time. This consideration suggests that the time effects could be satisfactorily incorporated into $T_{f s}$ as envisaged by Eq. (12). The data presented in this form suggests that the frost density is not strongly correlated with the relative humidity. 
Figure 3 reveals that at $\theta=1$, the value of $\rho_{f} / \rho_{\text {ice }}$ approaches 0.37 , which is considerably less than the value of unity (corresponding to ice). An abrupt density transition (jump) in frost density is expected as $\theta \rightarrow 1$. This abrupt transition near $\theta=1$ is advocated by the measurements of Östin and Anderson (1991), as alluded to earlier. Thus the data of Hermes et al. (2009) appears to be consistent with the character of the frost data of Östin and Anderson (1991) with regard to the possibility of a jump in frost density as the frost surface approaches the melting temperature.

\subsection{Comparison with the Data of Lee et al. (2003)}

In an effort to further validate the present correlation for frost density with an independent set of observations, the correlation Eq. (12) was compared to the measurements of frost density by Lee et al. (2003). To the author's knowledge, these are the only measurements on frost density at relatively high temperature, other than the data of Hermes et al. (2009) already discussed in the preceding sections, where both the frost density and frost surface temperature were simultaneously measured. The same correlation constants $c_{2}$ and $c_{3}$ defined by Eq. (11) are considered in the prediction of frost density according to Eq. (12).

Two sets of data are considered here for comparison. One set of data corresponds to $T_{w}=-15^{\circ} \mathrm{C}, T_{\infty}=15^{\circ} \mathrm{C}, \omega_{\infty}=0.00633 \mathrm{~kg}$ (vapor) $/ \mathrm{kg}$ (dry air), and $u_{\infty}=2.5 \mathrm{~m} / \mathrm{s}$. The other set of data corresponds to $T_{w}=-20{ }^{\circ} \mathrm{C}, T_{\infty}=10^{\circ} \mathrm{C}, \omega_{\infty}=0.00528 \mathrm{~kg}$ (vapor) $/ \mathrm{kg}$ (dry air), and $u_{\infty}=1.75 \mathrm{~m} / \mathrm{s}$. The flow Reynolds numbers corresponding to the air velocities of 1.75 $\mathrm{m} / \mathrm{s}$ and $2.5 \mathrm{~m} / \mathrm{s}$ are respectively $0.31 \times 10^{5}$ and $0.44 \times 10^{5}$. Uncertainty in the measured frost density is estimated at $6.9 \%$, and uncertainty in the frost surface temperature is estimated at $4.4 \%$. 
Figure 4 displays a comparison of the proposed correlation with the data of Lee et al. (2003) at the two Reynolds numbers considered, corresponding to $\xi=0.4$ and 0.56 which are considerably higher relative to that encountered in the data of Hermes et al. (2009). The data cover a range of $\theta$ from to 0.1 to 0.5 , and suggest that the frost density at a constant $\theta$ increases as the Reynolds number increases. This trend is predicted by the proposed correlation, which agrees reasonably well with the data, except for very small values of $\theta$. The predicted values of $\rho_{f} / \rho_{\text {ice }}$ at $\theta=1$ for $\xi=0.4$ and 0.56 are respectively about 0.43 and 0.44, which compare to the value of 0.37 for $\xi=0.04$ (shown in Fig. 3). The relatively lower range of $\theta$ arising in the data of Lee at al. (2003) may be regarded as complementing the data of Hermes et al, (2009) which span a range of $\theta$ from 0.5 to unity.

\subsection{Character of Frost Density and Frost Porosity}

The general character of frost density as predicated by the proposed correlation (Eq. 12) is illustrated in Fig. 5a covering $0 \leq \theta \leq 1$ and $0.05 \leq \xi \leq 1$. The results suggest that the frost density variation due to flow Reynolds number is indeed remarkable, and that the density variation (at a constant $\theta$ ) displays the existence of a peak in the neighborhood of $\theta$ around 0.7 to 0.8 . As $\xi \rightarrow 1$ (Reynolds number nearing the critical value), the frost density varies linearly with the dimensionless frost surface temperature. Measurements such as those of Biguria and Wentzel (1970) suggest that the frost density in turbulent flow $(\xi>1)$ exceed those in laminar flow, as is to be expected.

Figure $5 \mathrm{~b}$ represents the variation of frost porosity as obtained by the proposed formulation (Eqs. 1 and 12) covering $0 \leq \theta \leq 1$ and $0.05 \leq \xi \leq 1$. In obtaining these results, values of $\rho_{\text {ice }}=917 \mathrm{~kg} / \mathrm{m}^{3}$, and $\rho_{g} \approx 1.2 \mathrm{~kg} / \mathrm{m}^{3}$ are considered. At a given frost surface 
temperature, the frost porosity decreases with an increase in flow Reynolds number. It is noticed that at a given Reynolds number the frost porosity decreases with an increase in the frost surface temperature. This result is consistent with the phenomenon of frost densification as the frost growth proceeds. Measurements on packed beds suggest that thermal dispersion effect increases as the porosity increases (Du et al., 2003). An increase in thermal dispersion amounts to an increase in thermal conduction, which in turn implies an increase in frost density. This consideration points out a plausible explanation for the underprediction of the low density data of Lee et al. (2003) corresponding to low frost surface temperature.

Thermal dispersion effects are intimately related to eddy convection (Kandula 2010), and were treated by Cheng and Vortmeyer (1988) along with wall channeling effects (existence of a peak velocity in a region close to the external boundary, analogous to a wall jet in single-phase flow). Convection in variable porosity media, including channeling effects were considered by Vafai (1984).

\section{Discussion}

The practical and physical significance of the proposed correlation lies in its application to frost modeling. The author (Kandula 2011a) recently incorporated the proposed frost density model in conjunction with the newly-developed effective frost thermal conductivity model (Kandula, 2010) to accurately predict the frost growth, frost densification, frost surface temperature and heat flux when compared to five sets of test data from various investigators covering a fairly wide range of variables (wall temperature, air humidity, air velocity, and air temperature). The effective frost conductivity model was based on a porous packed bed model of Zehner and Schlunder (1970), see also Kandula (2011b). The 
satisfactory prediction of the frost parameters lends confidence in the proposed frost density correlation.

It should be pointed out that the present correlation for frost porosity is limited to laminar forced convection, and does not address the conditions of turbulent flow. Also natural convection effects (laminar/turbulent), driven by the temperature differential (between the air and the frost surface) are excluded from consideration in the present formulation.

The plate temperature becomes especially important at very low plate temperatures (approaching cryogenic temperatures), for which sufficient data on frost density is presently unavailable. A detailed investigation of the low temperature effects is beyond the scope of the present investigation. More experimental data on frost density (with simultaneous measurement of frost surface temperature) covering a wide range of plate temperatures will be of great help in extending the generality of frost density correlations for use in practical applications.

\section{Conclusions}

The proposed correlation for water frost porosity in terms of dimensionless frost surface temperature and flow Reynolds number, applicable to laminar flow, satisfactorily describes the experimental data on frost density. It is revealed that flow Reynolds number has an important effect on the frost porosity, and that at the critical Reynolds number the frost density is described by a linear variation with dimensionless frost temperature. The results also suggest that the effect of relative humidity of air on frost porosity is rather unimportant in the framework of the present correlation, suggesting that the air humidity effects are indirectly absorbed into the frost surface temperature. 


\section{Acknowledgement}

The author thanks the reviewers for helpful suggestions in improving the manuscript. This work was funded by NASA Kennedy Space Center, with Mark Collard as Project Manager.

\section{References}

Aoki, K., A study on frost formation (the process of frost formation involving the phenomena of water permeation and freezing), Bull. JSME, Vol. 26, pp. 87-93, 1983.

Biguria, G. and Wenzel, L.A., Measurement and correlation of water frost conductivity and density, I\&EC Fundamentals, Vol. 9, pp. 129-138, 1970.

Brian, P.L.T., Reid, R.C., and Brazinsky, I., Cryogenic frost properties, Cryogenic Technology, Vol. 5, pp. 205-212, 1969.

Brian, P.L.T., Reid, R.C., and Shah, Y.T., Frost deposition on cold surfaces, IEC Fundamentals, Vol. 9, No. 3, pp. 375-380, 1970.

Cheng, C-H and Cheng, Y-C, Predictions of frost growth on a cold plate in atmospheric air, International Communications in Heat Mass Transfer, Vol. 28, No. 7, pp. 953-962, 2001. Cheng, $\mathrm{C}-\mathrm{H}$ and $\mathrm{Wu}, \mathrm{K}-\mathrm{K}$, Observations of early-stage frost formation on a cold plate in atmospheric air flow, ASME J. of Heat Transfer, Vol. 125, pp. 95-102, 2003.

Cheng, P. and Vortmeyer, D., Transverse thermal dispersion and wall channeling in a packed bed with forced convective flow, Chem. Engng. Sci., Vol. 9, pp. 2523-2532, 1988.

Cheng, P. and Hsu, C-T, The effective stagnant thermal conductivity of porous media with periodic structures, J. Porous Media, Vol. 2, pp. 19-38, 1999. 
Du, J., Hu, X., and Wang, B-X, Thermal dispersion model for single phase flow in porous media, Heat Transfer - Asian Research, Vol. 32, pp. 545-552, 2003.

Hayashi, Y., Aoki, A., Adachi, S., and Hori, K., Study of frost properties correlating with frost formation types, ASME J. of Heat Transfer, Vol. 99, pp. 239-245, 1977.

Hermes, C. J. L., Piucco, R. O., Barbosa, Jr., J. R., and Melo, C., A study of frost growth and densification on flat surfaces, Experimental Thermal and Fluid Science, Vol. 33, pp. 371$379,2009$.

Hosoda, T. and Uzuhashi, H., Effects of frost on the heat transfer coefficient, Hitashi Review, Vol. 16, No. 6, pp. 254-259, 1967.

Iragorry, J., Tao, Y-X, and Jia, S., A critical review of properties and models for frost formation analysis, HVAC \& R Research, Vol. 10, No. 4, pp. 393-420, 2004.

Kandula, M., Effective thermal conductivity of frost considering mass diffusion and eddy convection, Special Topics and Reviews in Porous Media, Vol. 1, No. 4, pp. 321-336, 2010. Kandula, M., Frost growth and densification in laminar flow over flat surfaces, Int. J. Heat Mass Transfer, 2011a (in press).

Kandula, M., On the effective thermal conductivity of porous packed beds with uniform spherical particles, J. Porous Media, $2011 \mathrm{~b}$ (in press).

Kays, W. M. and Crawford, M. E., Convective Heat and Mass Transfer, McGraw-Hill, 2nd edition, New York, 1980.

Lee, K-S, Jhee, S., and Yank, D-K., Predictions of the frost formation on a cold flat surface, Int. J. Heat Mass Transfer, Vol. 46, pp. 3789-3796, 2003.

Östin, R. and Anderson, S., Frost growth parameters in a forced air stream, Int. J. of Heat Mass Transfer, Vol. 34 (4/5), pp. 1009-1017, 1991. 
Sahin, A., An experimental study on the initiation and growth of frost formation on a horizontal plate, Experimental Heat Transfer, Vol. 7, pp. 101-119, 1994.

Schlichting, H., Boundary Layer Theory, 7th edition, McGraw-Hill, New York, 1979.

Sherif, S.A., Raju, S. P., Padki, M. M., and Chan, A. B., A semi-empirical transient method for modeling frost formation on a flat plate, Rev. Int. Froid, Vol. 16, No. 5, pp. 321-329, 1993.

Trammel, G. I., Canterbury, J., and Killgore, E. M., Heat transfer form humid air to a horizontal flat plate held at subfreezing temperatures, ASHRAE Trans., Vol. 73, part I, IV.3.1-IV.3.6, 1967.

Vafai, K., Convective flow and heat transfer in variable-porosity media, J. Fluid Mechanics, Vol. 147, pp. 233-259, 1984.

Yang, D-K and Lee, K-S, Dimensionless correlations of frost properties on a cold plate, Int. J. of Refrigeration, Vol. 27, pp. 89-96, 2004.

Yang, D-K., and Lee, K-S., Modeling of frosting behavior on a cold plate, Int. J.

Refrigeration, Vol. 28, pp. 396-402, 2005.

Yang, D-K., Lee, K-S., and Cha, D-J., Frost formation on a cold surface under turbulent flow, Int. J. Refrigeration, Vol. 29, pp. 164-169, 2006.

White, F.M., Viscous Fluid Flow, 2nd edition, McGraw-Hill, New York, 1991.

Zehner, P., and Schlunder, E.U., Thermal conductivity of granular materials at moderate temperatures, Chemie Ingr. Tech., Vol. 42, pp. 933-941, 1970 (in German). 


\section{Figure Captions}

Figure 1. Schematic of porous frost layer, frost growth and frost densification.

Figure 2. Frost density variation according to the correlation of Hayashi et al. (1977):

(a) frost density variation with frost surface temperature, (b) comparison with

measurements of Hermes et al. (2009), adapted from Hermes et al. (2009).

Figure 3. Comparison of the proposed correlation with the data of Hermes et al. (2009).

Figure 4. Comparison of the proposed correlation with the data of Lee et al. (2003).

Figure 5a. Frost density dependence on temperature and Reynolds number according to the proposed correlation.

Figure 5b. Frost porosity dependence on temperature and Reynolds number according to the proposed correlation. 
mass transfer of vap or to the frost surface

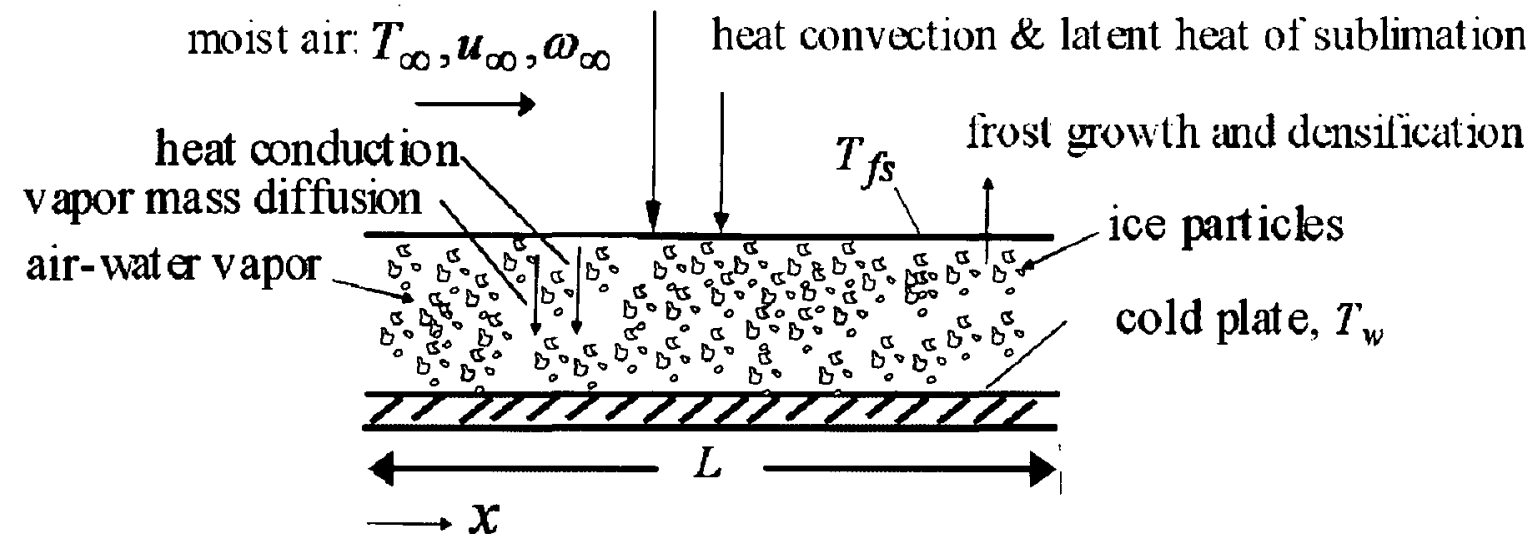

Figure1. Schematic of porous frost layer, frost growth and frost densification.

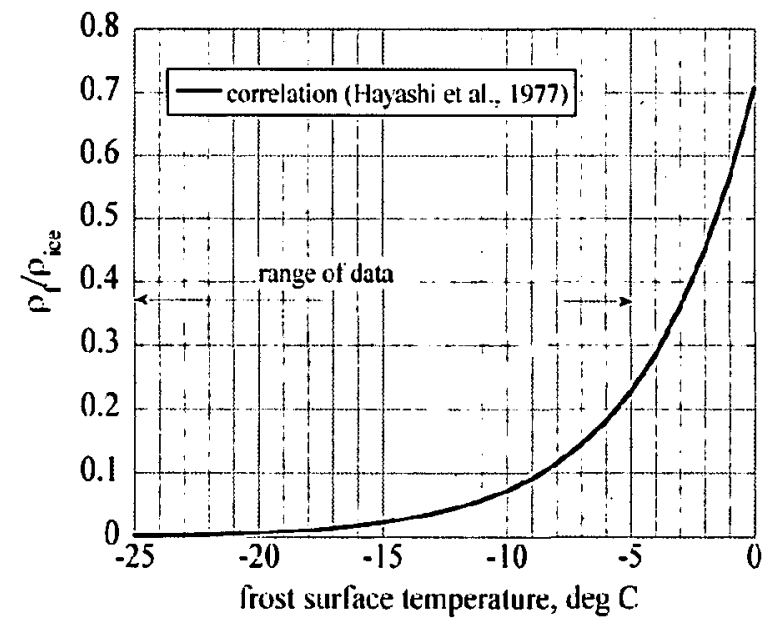

(a)

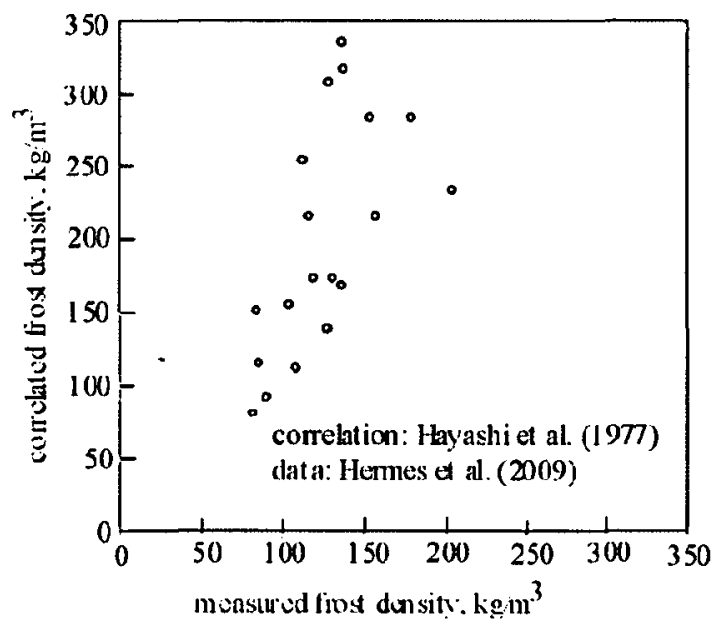

(b)

Figure 2. Frost density variation according to the correlation of Hayashi et al. (1977): (a) frost density variation with frost surface temperature, (b) comparison with measurements of Hermes et al. (2009), adapted from Hermes et al. (2009). 


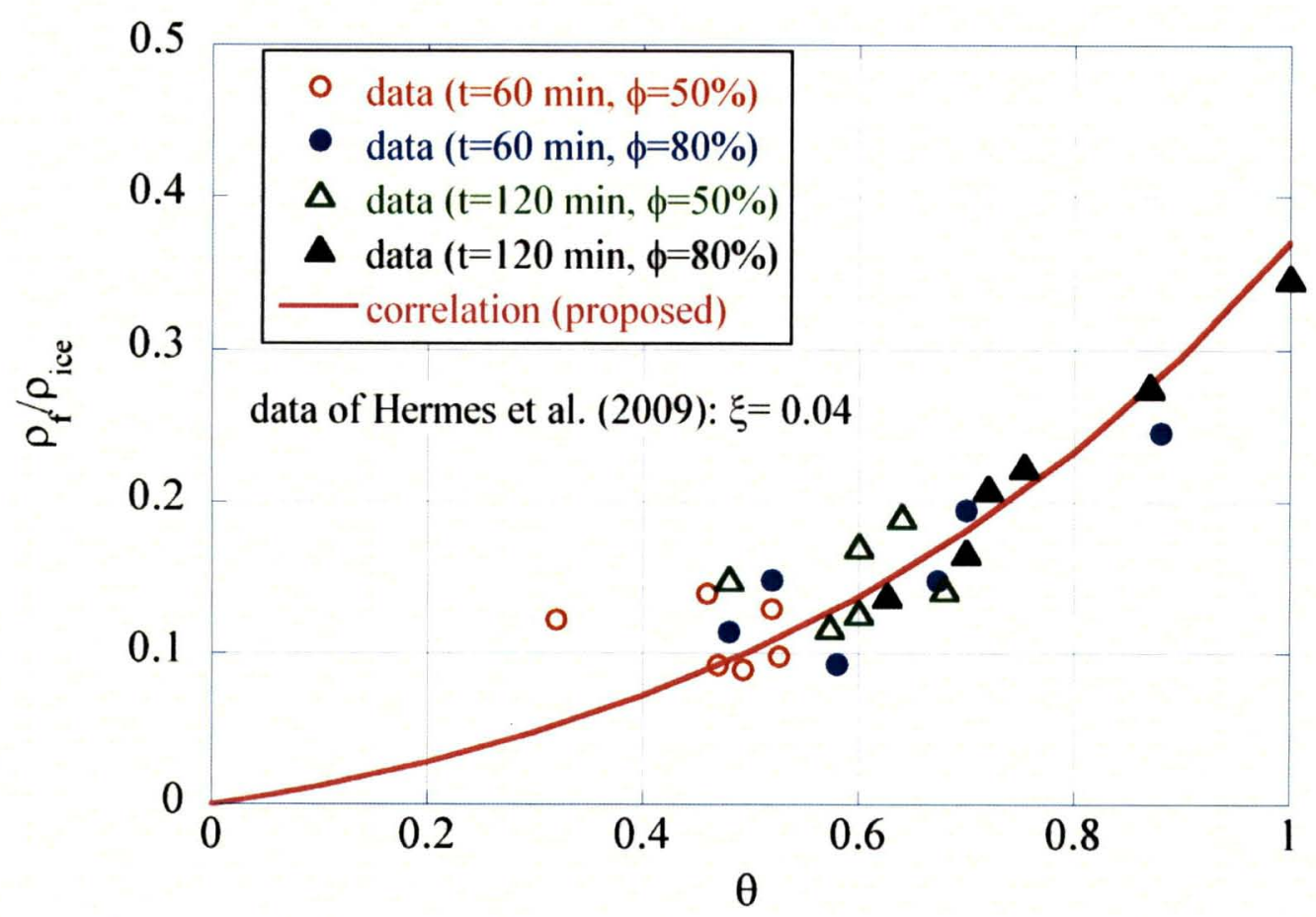

Figure 3. Comparison of the proposed correlation with the data of Hermes et al. (2000).

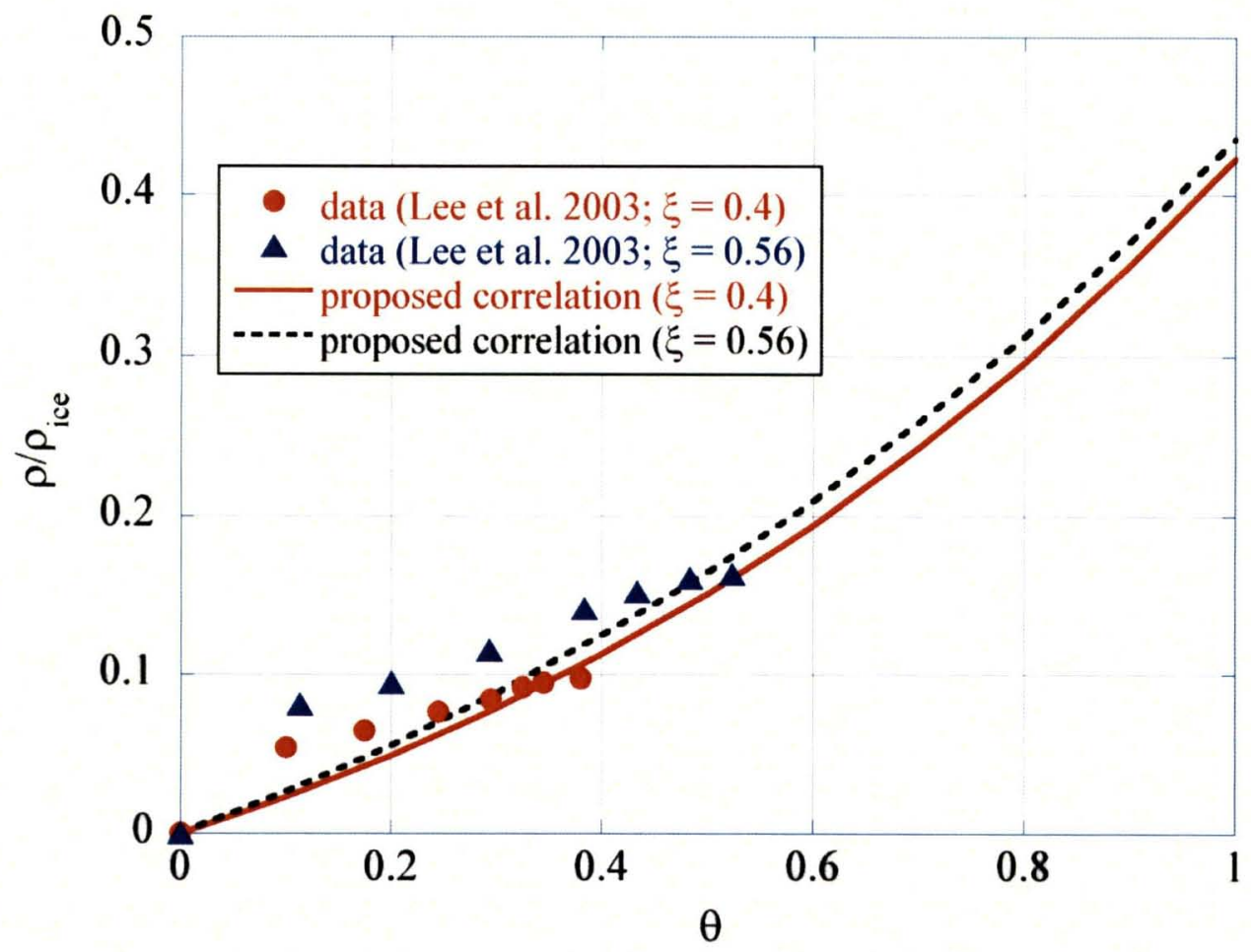

Figure 4. Comparison of the proposed correlation with the data of Lee et al. (2003). 


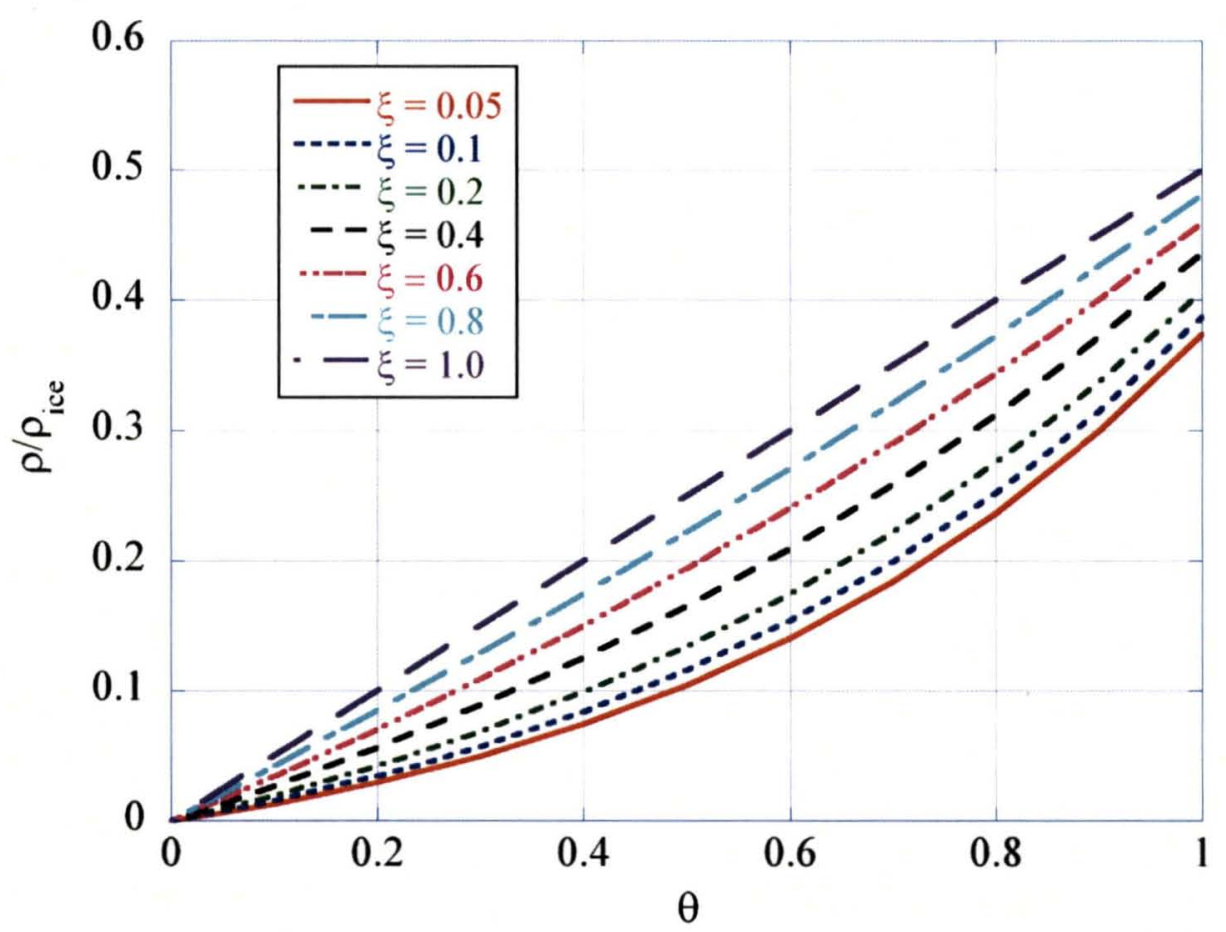

Figure 5a. Frost density dependence on temperature and Reynolds number according to the proposed correlation.

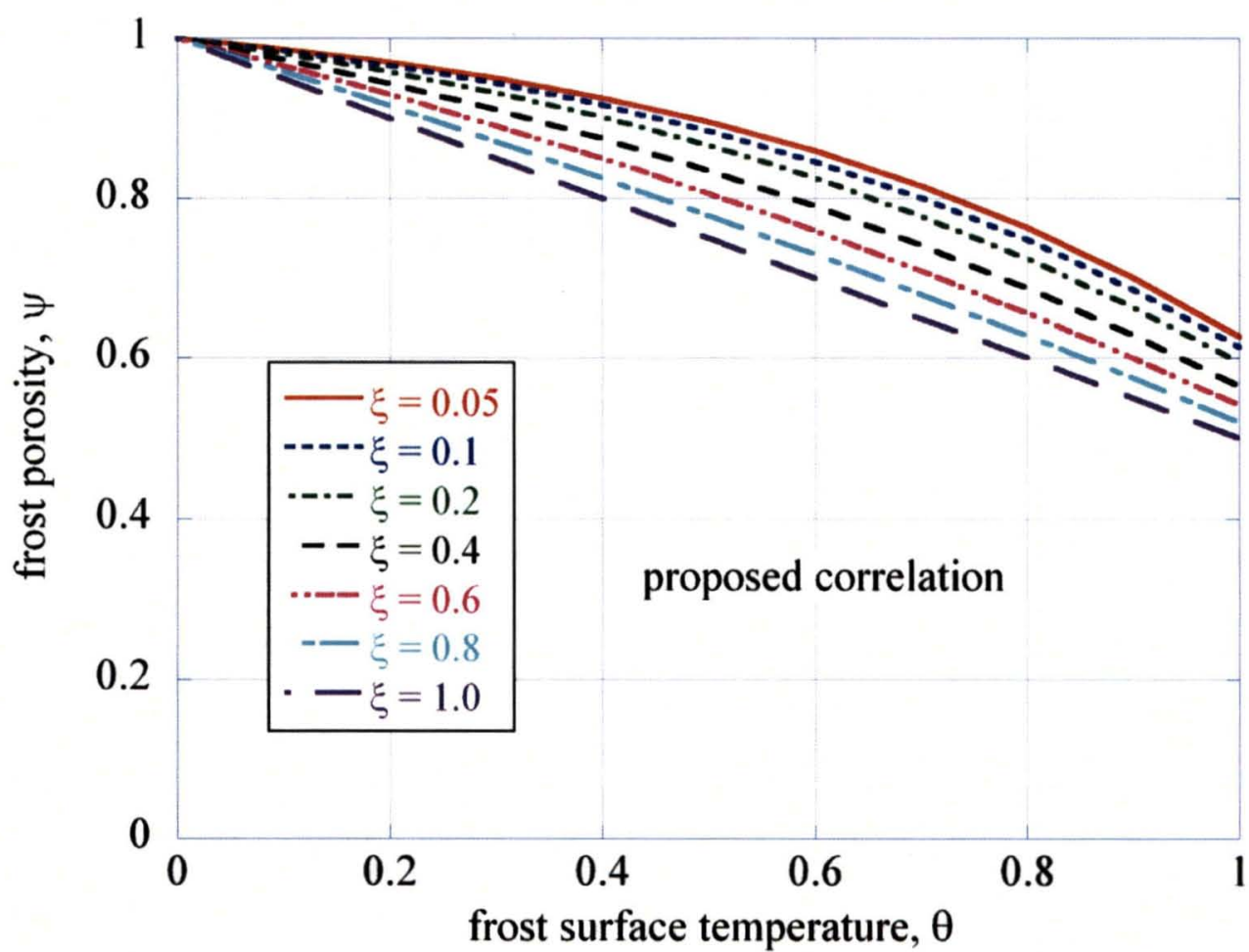

Figure 5b. Frost porosity dependence on temperature and Reynolds number according to the proposed correlation. 